\title{
Lung resection after pneumonectomy: the pivotal role of extracorporeal membrane oxygenation - a case report
}

\author{
Giorgio Lo Iacono ${ }^{1}$, Luca Bertolaccini ${ }^{1}$, Francesco Petrella ${ }^{1,2}$, Domenico Galetta ${ }^{1}$, Marco Venturino ${ }^{3}$, \\ Lorenzo Spaggiari ${ }^{1,2}$ \\ ${ }^{1}$ Department of Thoracic Surgery, IEO, European Institute of Oncology IRCCS, Milan, Italy; ${ }^{2}$ Department of Oncology and Hemato-Oncology, \\ University of Milan, Milan, Italy; ${ }^{3}$ Department of Anaesthesia, IEO, European Institute of Oncology IRCCS, Milan, Italy \\ Correspondence to: Giorgio Lo Iacono, MD. IEO, European Institute of Oncology IRCSS, Via Giuseppe Ripamonti 435, Milan 20141, Italy. \\ Email: giorgio.loiacono@ieo.it.
}

\begin{abstract}
Patients treated for lung cancer have a specific risk to develop second primary lung cancer or a recurrence of prevision tumor, the latter depending on the initial tumor stage. The increase in survival after pneumonectomy can lead the thoracic surgeon to face the chance to proceed to a pulmonary resection after pneumonectomy. Before surgery, it is essential to accurately understand what the objectives of the surgery are, to assess whether the benefits linked to the surgery can effectively overcome the theoretical risks of the procedure itself. The intention can generally also be considered curative, in the case of a single lung lesion, or it can be understood as the acquisition of a new tissue sample in order to optimize the therapeutic path, as in the case of our patient. In our case, we had to acquire a new tissue sample on a patient that 2 years before had undergone a left pneumonectomy for primary lung cancer after induction therapy. For this reason, we decided to try to increase patient safety by adding extracorporeal membrane oxygenation (ECMO) support for single lung surgery. Following our experience in major thoracic surgery with extracorporeal circulation, we decided to submit the patient to a right upper lobe thoracoscopic wedge resection with veno-venous ECMO support. With a careful selection of patients and minimizing the impact of surgery on the patient, this kind of surgery can be performed, achieving the superior patient quality of life after surgery, low risks, complete resection and the chance to optimize medical treatment if needed.
\end{abstract}

Keywords: Pneumonectomy; lung cancer; video-assisted thoracoscopic surgery (VATS); extracorporeal membrane oxygenation (ECMO); case report

Received: 15 December 2019; Accepted: 30 December 2019; Published: 05 July 2020.

doi: $10.21037 /$ jovs.2019.12.11

View this article at: http://dx.doi.org/10.21037/jovs.2019.12.11

\section{Introduction}

Patients treated with surgery for lung cancer have a specific risk to develop second primary lung cancer or a recurrence of prevision tumour, depending on the initial tumour stage (1). If this event occurs after a pneumonectomy, several considerations should be done to choose the correct approach for diagnosis and cure. These patients should not be automatically excluded from surgery, but they should be carefully selected based on lung cancer stage and cardiopulmonary reserve $(2,3)$. Before surgery, it is essential to accurately understand what the objectives of the surgery are, to assess whether the benefits linked to the surgery can effectively overcome the theoretical risks of the procedure itself. If feasible, the attempt to gain a complete resection should always be tried. Even if single lung surgery after pneumonectomy is dated in the 1950s (4), it remains a rare entity in thoracic surgery. Even if in the past, we performed this kind of surgery with single lung ventilation (5), or anecdotally experiences are described in literature on cardiopulmonary bypass (CPB) (6). In order to improve patient safety and stability during surgery, we introduced the use of video-assisted thoracoscopic surgery (VATS), to reduce the sequelae of surgery, associated with 
extracorporeal membrane oxygenation (ECMO).

\section{Case presentation}

We present a case of a 60 -year-old patient with a complex oncological history. At the diagnosis of primary adenocarcinoma of the left lung, for the involvement of both lobes, he was started with platinum-based chemotherapy (four cycles), then switched to biological therapy (gefitinib). When he arrived at our observation, the excellent response to treatment, the clinical negative nodal status and extra-thoracic staging with the excellent cardiorespiratory functional tests, bring us to perform a radical left pneumonectomy with lymph nodes radical dissection (final staging: ypT2 ypN2a2). Mediastinal adjuvant radiotherapy was administered. During followup for (26 months after surgery, on maintenance with gefitinib) multiple small parenchymal nodules suspected for recurrence were found at CT-scan. Extra-thoracic and nodal staging were negative. Due to suspected disease progression in the residual lung, after the multidisciplinary consult, it was decided to proceed to a new tissue sampling, to optimise medical treatment. The small dimensions of the nodules associated with the optimal performance status of the patient allowed us to perform a surgical biopsy. Respiratory function test evidenced a forced expiratory volume in the 1 st second (FEV1) of $2.38 \mathrm{~L}$ (77\% of predicted), diffusing capacity or transfer factor of the lung for carbon monoxide (DLCO) 62\%, DLCO/alveolar volume (VA) $105 \%$. The patient underwent a right upper lobe thoracoscopic wedge resection ECMO-assisted. In the beginning, anaesthesia was based on single lumen tube intubation with $\mathrm{FiO}_{2} 40 \%$ ventilation. Then a veno-venous ECMO (Cardiohelp, Getinge AB, Göteborg, Sweden) circuit was established through two heparin-coated percutaneous cannulas, one in the right femoral vein $(21 \mathrm{Fr}$, MAQUET Cardiopulmonary Getinge Group, Göteborg, Sweden) and internal right jugular vein (15 Fr, MAQUET Cardiopulmonary Getinge Group, Göteborg, Sweden). ECMO was started, and once fully operational, pulmonary ventilation has been stopped, to resume after the end of surgery and allow the exclusion of ECMO. The total time of extracorporeal circulation was 13 minutes. Surgical technique was standard for atypical segmentectomy with use of endoscopic surgical staplers. A single drain was placed at the end of the procedure in the mid-axillary line. The patient was extubated in the operatory room and then admitted to the intensive care unit for clinical observation after surgery. The postoperative stay was uneventful with attention to potential respiratory and circulatory failure. The patient was discharged in the seventh postoperative day in excellent clinical condition. It was identified a recurrence of adenocarcinoma with T790M resistance, and medical treatment was then corrected on this evidence. The patient is still alive under medical treatment, in follow-up with oncologist. All procedures performed in this study were in accordance with the Helsinki Declaration (as revised in 2013). Written informed consent was obtained from the patient for publication of this manuscript and any accompanying images.

\section{Discussion}

A tumour can recur. Very often, patients who undergo pneumonectomy have more advanced tumours. In these patients, the risk of recurrence is more significant concerning the stage of the disease. The increase in survival after pneumonectomy, thanks to the improvement of diagnostic and therapeutic techniques in lung cancer, especially in the adjuvant regimen, have brought to the attention of the thoracic surgeon more and more patients with long-term recurrences or new primary pulmonary cancers of the remaining lung. The preoperative study of a suspected lesion for a second primary tumour or suspected recurrence is similar to the staging of the initial tumour. It is necessary to carry out a correct staging of the disease to determine whether the patient has an advanced disease in the chest or, extrathoracic sites. The peculiarity of these patients is, for obvious reasons, the reduced respiratory function and the difficulty, not so technical, but anaesthetic in the intraoperative management of ventilation. Several techniques have been developed over time for the approach of these patients. It is undoubtedly necessary to make a distinction on resections after pneumonectomy between atypical resections and peripheral lesions or anatomical resection and central lesions. In the last ones, extracorporeal support is probably necessary (6). The use of $\mathrm{CPB}$ exposes the patient to the risk of complications due to heparinisation and typical sequelae of extracorporeal circulation. Something was needed to support ventilation and reduce patient stress during the operation. Our idea was to join the use of extracorporeal circulation, less risky and flexible than $\mathrm{CPB}$, and the use of minimal-invasive techniques to reduce the physical impact of surgery. Based on our experience in major carinal resection, and the minimal impact on the patient, we decide to use 


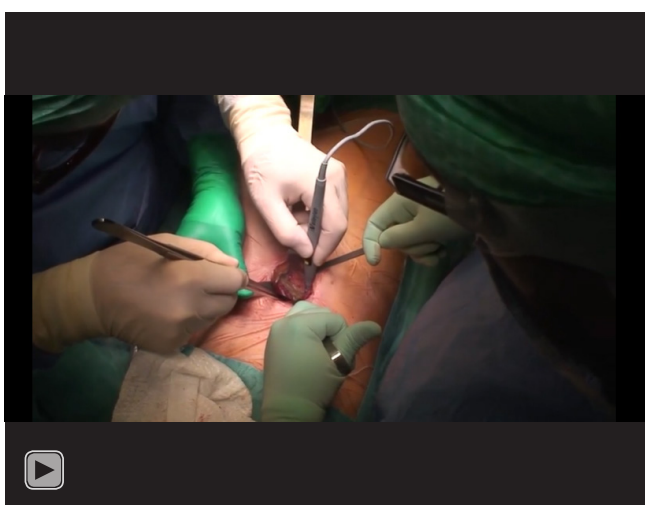

Video 1 Single lung wedge resection of the left upper lung using a veno-venous ECMO (7). ECMO, extracorporeal membrane oxygenation.

ECMO (Video 1). This device in the last years has been increasingly taken into consideration in new therapeutic areas. The classic fields of application of ECMO are endstage pathologies to support cardiac or respiratory function as a bridge to heart and/or lung transplantation (8). However, the experience of use of extracorporeal assistance for pulmonary resection is limited in oncological field, reserved to some challenging procedure such us single lung surgery or complex tracheobronchial resection to achieve proper oxygenation and hemodynamic support during complex cases. In our experience with a carinal resection on ECMO, we have appreciated high hemodynamic stability, excellent tolerability of extracorporeal support in the face of a low need for anticoagulant. Based on these dates, we have decided to support this single lung surgery with ECMO. Due to altered respiratory mechanics, access to the pleural cavity must be minimally invasive to minimise pain and surgical damage to the chest wall musculature. Thoracotomy should be avoided.

\section{Conclusions}

ECMO is more and more used during thoracic surgical procedures as an alternative to $\mathrm{CPB}$ for major carinal surgery and single lung procedures without in-field ventilation. Several evaluations should be done to consider a second operation after pneumonectomy. Above all, the possibility of modifying the natural history of the disease, especially in the oncology field. For this reason, as we have done in the past, we believe that single lung surgery must be considered to achieve a complete resection, when feasible, or to evaluate the possibility of having new tissue to retype the disease in case of suspected recurrence, especially in the age of biological therapies and immunotherapy. For this reason, we believe that ECMO support can be spent as respiratory support in patients who must undergo single lung surgery. It gives the possibility to proceed also to anatomical resection without any concern of time or respiratory instability during surgery, without increasing the risk of complication linked to extracorporeal circulation. This is the first experience published with the common use of VATS and ECMO for single lung surgery, we believe that new reports in this regard will only strengthen the evidence on the joint use of these two technologies.

\section{Acknowledgments}

Funding: This work was partially supported by the Italian Ministry of Health with Ricerca Corrente and 5x1000 funds.

\section{Footnote}

Conflicts of Interest: All authors have completed the ICMJE uniform disclosure form (available at https://jovs. amegroups.com/article/view/10.21037/jovs.2019.12.11/ coif). LB serves as an unpaid editorial board member of Journal of Visualized Surgery from June 2019 to May 2021. The other authors have no conflicts of interest to declare.

Ethical Statement: The authors are accountable for all aspects of the work in ensuring that questions related to the accuracy or integrity of any part of the work are appropriately investigated and resolved. All procedures performed in this study were in accordance with the Helsinki Declaration (as revised in 2013). Written informed consent was obtained from the patient for publication of this manuscript and any accompanying images.

Open Access Statement: This is an Open Access article distributed in accordance with the Creative Commons Attribution-NonCommercial-NoDerivs 4.0 International License (CC BY-NC-ND 4.0), which permits the noncommercial replication and distribution of the article with the strict proviso that no changes or edits are made and the original work is properly cited (including links to both the formal publication through the relevant DOI and the license). See: https://creativecommons.org/licenses/by-nc-nd/4.0/. 


\section{References}

1. Loukeri AA, Kampolis CF, Ntokou A, et al. Metachronous and synchronous primary lung cancers: diagnostic aspects, surgical treatment, and prognosis. Clin Lung Cancer 2015;16:15-23.

2. Donington JS, Miller DL, Rowland CC, et al. Subsequent pulmonary resection for bronchogenic carcinoma after pneumonectomy. Ann Thorac Surg 2002;74:154-8; discussion 158-9.

3. Spaggiari L, Grunenwald D, Girard P, et al. Cancer resection on the residual lung after pneumonectomy for bronchogenic carcinoma. Ann Thorac Surg 1996;62:1598-602.

4. RZEPECKI W. Is partial pulmonary resection after contralateral pneumonectomy in pulmonary tuberculosis

doi: $10.21037 /$ jovs.2019.12.11

Cite this article as: Lo Iacono G, Bertolaccini L, Petrella F, Galetta D, Venturino M, Spaggiari L. Lung resection after pneumonectomy: the pivotal role of extracorporeal membrane oxygenation-a case report. J Vis Surg 2020;6:33. feasible and indicated? Acta Med Pol 1960;1:259-67.

5. Spaggiari L, Solli P, Veronesi G. Single lung resection of second primary after pneumonectomy for lung cancer. Ann Thorac Surg 2003;75:1358; author reply 1358.

6. Spaggiari L, Rusca M, Carbognani P, et al. Segmentectomy on a single lung by femorofemoral cardiopulmonary bypass. Ann Thorac Surg 1997;64:1519.

7. Lo Iacono G, Bertolaccini L, Petrella F, et al. Single lung wedge resection of the left upper lung using a veno-venous ECMO. Asvide 2020;7:067. Available online: http://www. asvide.com/watch/33106

8. Rosskopfova P, Perentes JY, Ris HB, et al. Extracorporeal support for pulmonary resection: current indications and results. World J Surg Oncol 2016;14:25. 